\title{
Os desafios do uso do Qr code encontrados por professores no ensino remoto
}

\author{
The challenges of teachers using QR Codes in a distance education \\ environment
}

Carla Denize Ott Felcher (1D https://orcid.org/0000-0002-9733-94

Universidade Aberta do Brasil/Universidade Federal de Pelotas

e-mail - carlafelcher@gmail.com

Ana Cristina Medina Pinto (iD https://orcid.org/0000-0003-4557-4668

Universidade Aberta do Brasil/Universidade Federal de Pelotas

e-mail - cpinto.ana@gmail.com

Rozane da Silveira Alves (D) https://orcid.org/0000-0001-9409-3495

Universidade Federal de Pelotas

e-mail - rsalvex@gmail.com

\section{Resumo}

O objetivo deste artigo é analisar os desafios do uso do QR Code encontrados por professores no ensino remoto. Considerando que a pandemia de Covid-19 trouxe diversos infortúnios à sociedade, em especial aos sistemas de ensino, cujas aulas presenciais estão paralisadas desde março, as tecnologias digitais, muitas vezes ignoradas, passaram a ser fundamentais para manter o vínculo com o estudante. Os dados examinados nesta investigação, sob a óptica da Teoria Fundamentada, foram produzidos em um curso de formação continuada, no formato EaD, oferecido aos professores da rede pública do Brasil durante os meses de abril e maio de 2020. Esse curso teve como objetivo apresentar os recursos e aplicações do QR Code, um código de resposta rápida, capaz de armazenar um grande volume de informações. Os resultados indicaram que a comunicação entre professores e alunos foi um grande desafio, pois muitos estudantes não tinham acesso à internet naquele momento, inviabilizando o recebimento das propostas planejadas pelos professores com o uso do QR Code. Entretanto, alguns professores adaptaram as propostas e as desenvolveram com públicos distintos, conseguindo, assim, vivenciar as possibilidades pedagógicas do QR Code. Por fim, é necessário e urgente que o ensino seja reavaliado, notadamente o ensino presencial, de modo que as tecnologias digitais sejam um meio significativo em prol da aprendizagem, para além dos tempos de pandemia.

Palavras-chave: Tecnologia. Ensino. Professores.

\section{Abstract}

This paper seeks to analyze the challenges faced by teachers using QR Codes in a distance education environment. The misfortunes brought to society by the Covid-19 pandemic, 
especially to educational systems, have made the often ignored digital technologies fundamental to keep teacher-student relations alive since classes were interrupted in March. The data examined in this investigation and supported by the Grounded Theory were produced in an internet-based continuing education course, which was offered to public school teachers in Brazil during the months of April and May 2020. The course aimed to present the features and applications of the QR Code, a quick response code capable of storing large amounts of information. The results indicate that communication between teachers and students posed a considerable challenge, as many students did not have access to the Internet at that time, making it impossible to receive the proposals planned by teachers using the QR Code. However, some teachers adapted their proposals and developed them with different audiences, thus managing to experience the pedagogical possibilities of the QR Code. Finally, it is necessary and urgent that teaching be reevaluated, notably face-to-face teaching so that digital technologies can be a significant means for learning even after the pandemic scenario is overcome.

Key words: Technology. Teaching. Teachers.

\title{
Introdução
}

A covid-19 é a doença cujo vírus causador é conhecido como o novo coronavírus. A velocidade de propagação e contaminação em nível exponencial acabou por instalar uma pandemia mundial, que teve o seu início na China, no final de dezembro de 2019 (WHO, 2020). Devido ao grande número de casos confirmados em todo o mundo, a Organização Mundial de Saúde (OMS) declarou a situação como uma pandemia. No Brasil, os primeiros casos foram relatados em fevereiro de 2020 e, na primeira quinzena de outubro do mesmo ano, já foram confirmados mais de 5 milhões de infectados e mais de 150 mil mortos, segundo Who (2020).

Com o objetivo de preservar vidas, a OMS indicou que os países deveriam intensificar os hábitos de higiene, lavando as mãos corretamente, bem como adotar o isolamento social e evitar aglomerações de pessoas (WHO, 2020). Nesse sentido, o Ministério da Educação (MEC) publicou a portaria $n^{\circ} 343$, de 17 de março de 2020, que estabeleceu a substituição de aulas presenciais por aulas que utilizem meios e tecnologias de informação e comunicação, pelo prazo de 30 dias ou, em caráter excepcional, podendo ser prorrogada enquanto durar a pandemia (BRASIL, 2020). Passados os 30 dias, as aulas continuaram prorrogadas, em razão de que:

\begin{abstract}
O novo coronavírus torna a escola um dos espaços mais temidos pelo risco da transmissão, pois a sua multiplicidade e heterogeneidade cria vínculos entre aqueles que são menos propensos aos sintomas graves da doença (jovens) a todos os demais que podem ser até mortalmente propensos. Crianças e jovens entram em contato diário com adultos de diferentes grupos familiares: professores, profissionais da educação, pais e mães, avós e avôs, parentes de maneira geral (ARRUDA, 2020, p. 258).
\end{abstract}

Com a suspensão das aulas presenciais, as escolas passaram a vislumbrar nas Tecnologias Digitais (TD) a oportunidade de aprendizagem para bilhões de alunos (SANTOS JÚNIOR; MONTEIRO, 2020). Isso por si só é uma quebra de paradigmas, já que, em muitas escolas do Brasil, os aparelhos celulares, por exemplo, eram proibidos. Segundo Pimentel e Feitoza (2017), em se tratando do uso de dispositivos móveis na escola, alguns estados brasileiros adotavam medidas para que não entrassem no ambiente escolar, sob a justificativa de que 
distraem o aluno e dificultam a aprendizagem, concepção essa validada pelo discurso de alguns professores que repudiam tais equipamentos tecnológicos. Para Feitosa e Pimenta (2017), o aparelho de telefonia móvel, por exemplo, oportuniza outros olhares sobre a capacidade de contribuir de forma interativa, objetiva e prática para a aprendizagem.

De acordo com Arruda (2020), as tecnologias tornaram-se as principais referências para a manutenção da conexão educacional, por intermédio do modelo denominado ensino remoto. Esse modelo de ensino se diferencia da Educação a Distância pelo caráter emergencial de usos e apropriações das tecnologias em circunstâncias especificas de atendimento onde outrora existia regularmente a educação presencial (ARRUDA, 2020). O ensino remoto é uma alternativa para atender os estudantes, ou seja, para entregar a eles os conteúdos curriculares e sua duração será igual ao tempo da crise causada pela pandemia.

As TD servem aos modelos e concepções que se desejam, atendendo tanto modelos tradicionais, quanto inovadores, centrados no aluno. Nesse contexto, destaca-se o QR Code, um código cuja utilização no âmbito educacional está ainda em fase inicial, conforme cita Saprudin, Goolamally, Latif (2014) e, mais recentemente, Garcia et al. (2018). A leitura de QR Code pode desempenhar importantes papéis na educação, possibilitando acesso à informação e ampliando a interação. Ainda segundo os mesmos autores, a criação de QR Codes representa uma interessante estratégia de ensino e de aprendizagem, cujos objetivos podem ser a produção e socialização de materiais, o desenvolvimento da autoria, da autonomia e do trabalho colaborativo (NICHELE; SCHLEMMER; RAMOS, 2015).

Em tempos de ensino remoto, os professores estão precisando se reinventar e apostar no uso das TD. Cabe questionar se esse uso tem sido viável ou não, já que a desigualdade social no Brasil tem se tornado ainda mais acentuada. Assim, o objetivo deste artigo é analisar os desafios do uso do QR Code encontrados por professores no ensino remoto. Para tanto, foram considerados os dados produzidos em uma formação continuada no formato EaD oferecida aos professores da rede pública do Brasil, nos meses de abril e maio de 2020.

\section{As tecnologias digitais no ensino}

Apesar de parecer que os seres humanos são aficionados pelas tecnologias (BORBA; ALMEIDA; GRACIAS, 2018), elas dividem opiniões e inclusive chegam a ser proibidas em alguns contextos, conforme já citado. Segundo Lévy (1993), o cúmulo da cegueira é atingido quando condenam a tecnologia, mas jamais a oralidade e a escrita, sendo que essas três técnicas, a oralidade, a escrita e a informática, são tecnologias da inteligência e estão sempre presentes no nosso dia a dia, embora com intensidade variável. "A vida humana não é possível sem qualquer uma delas" (LÉVY, 1993, p. 128). Essas tecnologias desempenham um papel fundamental nos processos cognitivos, mesmo nos mais cotidianos, por exemplo, nossa percepção da cidade muda, quando consultamos o Global Positioning System (GPS). 
Entre as justificativas para o uso das tecnologias digitais, destaca-se que a produção do conhecimento não é apenas um empreendimento individual, mas também coletivo, por isso a denominação coletivos pensantes, pois, de acordo com Lévy (1993, p.135), "fora da coletividade, desprovido de tecnologias intelectuais, 'eu' não pensaria". Ou, ainda, nas palavras de Borba e Villarreal (2005), as tecnologias estão impregnadas de humanidade, assim como os seres humanos estão impregnados de tecnologias, não existindo uma separação possível, logo o pensamento é sempre coletivo. Desse modo, segundo os autores, o conhecimento não é produzido por seres humanos solitários ou coletivos formados apenas por seres humanos, e sim por um coletivo seres-humanos-com-tecnologias.

Corroborando os argumentos em prol do uso das TD, a Base Nacional Comum Curricular (BNCC), em sua competência cinco, salienta que é preciso compreender, utilizar e criar tecnologias digitais de informação e comunicação de forma crítica, significativa, reflexiva e ética para se comunicar, acessar e disseminar informações, produzir conhecimentos, resolver problemas e exercer protagonismo e autoria na vida pessoal e coletiva (BRASIL, 2017). Com efeito, a defesa e o entendimento das TD no ensino-aprendizagem estão no sentido de incorporá-las de forma inovadora em sala de aula (KENSKI, 2013). Afinal, consoante Maltempi (2008), as tecnologias ampliam as possibilidades de ensinar e aprender.

$\mathrm{Na}$ verdade, as TD são alicerce para o ensino híbrido, um modelo de metodologia ativa que destaca a interação do ser humano com as tecnologias. Esse modelo envolve duas ou mais situações/objetos que necessariamente não precisam acontecer entre quatro paredes, ela pode ser adaptada a qualquer ambiente, graças à ubiquidade tecnológica, ou seja, encontra-se e adapta-se nos diversos ambientes, das mais diversas formas e necessidades (SCHIEHL; GASPARINI, 2016). Para os autores, o ensino híbrido não tem o propósito de substituir ou extinguir o ensino tradicional, mas o de reunir em um ambiente o melhor de ambos.

De acordo com Bacich e Moran (2015), a tecnologia permite integrar espaços e tempos, possibilitando que o ensinar e aprender aconteçam numa sala de aula ampliada, que se mescla, que é híbrida. Em consonância com tal pensamento, Garcia et al. (2018) afirmam que a educação formal é cada vez mais "blended", misturada, híbrida, visto que não acontece só no espaço físico da sala de aula, mas em múltiplos espaços, incluindo os digitais. Ainda conforme os autores, essa mescla é fundamental para abrir a escola para o mundo e para trazer o mundo para dentro da escola.

Em tempos de aulas presenciais paralisadas, o ensino híbrido ganhou evidência, inclusive essa tem sido a denominação do modelo educacional vigente em algumas redes de ensino, ou melhor, a solução para o sistema educacional. Porém, para Bacich (2020), o ensino híbrido é uma abordagem que está inserida no rol de metodologias ativas, uma concepção de aluno protagonista, de aulas que valorizam o aprender a aprender. No entanto, não tem sido incomum o uso das tecnologias digitais apenas para transportar uma aula expositiva a um grupo de alunos que não está presente na escola. 
As metodologias ativas englobam uma concepção de ensino e aprendizagem que valoriza as diferentes formas pelas quais os estudantes podem ser envolvidos no processo para que aprendam melhor, respeitando o ritmo, o tempo e o estilo de cada um (BACICH; MORAN, 2018). Nesse âmbito, Garcia et al. (2018) relatam uma prática que teve como objetivo proporcionar aos estudantes refletir sobre os aspectos teóricos importantes para o componente curricular, sem a necessidade de assistir a uma aula expositiva. O professor utilizou o QR Code e preparou uma tabela com as etapas do pensamento criativo e suas respectivas "definições". No entanto, essa tabela foi entregue aos estudantes apenas com o título das etapas; eles, em grupo, tinham de procurar as definições dos conceitos pelo campus (as quais estavam em formato de código) e finalizar o preenchimento da tabela, relacionando cada etapa a seu conceito. Assim, ao serem escaneados, os códigos apresentavam texto, links para vídeos ou imagens.

Estratégias pedagógicas como a relatada por Garcia et al. (2018) evidenciam que o uso das tecnologias ou de propostas inovadoras devem estar a serviço dos objetivos de aprendizagem. Nesse sentido, Felcher, Pinto e Folmer (2018) trazem duas propostas com o QR Code: uma delas possibilita trabalhar o conceito matemático plano cartesiano e pode ser desenvolvida com alunos do $8^{\circ}$ ou $9^{\circ}$ ano do ensino fundamental com o objetivo de fixar o conteúdo de uma forma mais divertida. Os estudantes em grupo recebem os códigos, os quais, escaneados, apresentam pontos a serem localizados no plano cartesiano, desenhado ao ar livre. A segunda proposta, também planejada para ser desenvolvida em grupo, consiste na realização de uma gincana, que pode ser adaptada para ser desenvolvida em qualquer componente curricular e ano da educação básica.

O QR Code pode ser empregado em diferentes níveis do ensino, componentes curriculares e conceitos em estudo. Em Bastos, Rapkiewicz e Benvenuti (2016), o código foi utilizado na Educação de Jovens e Adultos, em um projeto piloto, integrando as áreas de Língua Portuguesa e Cultura Digital, que teve como objetivo propiciar aos estudantes apropriar-se da integração de dispositivos móveis na educação. O QR Code foi utilizado para divulgar as produções textuais realizadas pelos alunos que foram postadas em um blog. Para ter acesso aos textos, os discentes criaram cartazes com códigos QR e afixaram nos corredores da escola para serem acessados por alunos do ensino regular (BASTOS; RAPKIEWICZ; BENVENUTI, 2016).

As possibilidades de uso do QR Code apresentadas mostram que a tecnologia digital não foi explorada de modo domesticado. A título de esclarecimento, segundo Borba, Silva e Gadanidis (2015), o uso domesticado consiste em utilizar a tecnologia da mesma forma e ancorada nas mesmas práticas que eram condicionadas por outras mídias. Um exemplo de uso domesticado da tecnologia digital é utilizar o código para envio de material a ser reproduzido pelo estudante, o que poderia ser realizado através de e-mail, material impresso, livro didático, entre outros.

A propósito, não é incomum o uso domesticado da TD no sistema educacional. Há uma tendência por parte dos professores de transformar as aulas expositivas em arquivos pdf ou pptx, repetindo procedimentos pedagógicos tradicionais, 
agora com o uso das TD. Os resultados de tais práticas não são os esperados pelos docentes e pelos estudantes, os quais se sentem insatisfeitos com os aparatos utilizados (KENSKI, 2013). Visando minimizar essa situação, Maltempi (2008) destaca a necessidade de avaliar o momento oportuno e proveitoso do uso de tecnologias, a fim de obter um retorno positivo e evitar que recebam rótulos de ineficazes ao processo educacional.

\section{Metodologia}

O presente estudo é de natureza qualitativa, tendo em vista a necessidade de obter informações descritivas, as quais estão vinculadas à compreensão, ao significado do fenômeno investigado, podendo abarcar a vida das pessoas, histórias, comportamentos, movimentos sociais, relações, interações, entre outros. Esta investigação se relaciona com o uso do QR Code pelos professores de um curso de formação continuada, participantes da pesquisa. Esse tipo de pesquisa é caracterizado por Bodgan e Biklen (1994): 1), para quem o ambiente natural é a fonte dos dados, sendo o investigador o instrumento principal; 2) as investigações são descritivas; 3 ) os investigadores se interessam mais pelo processo do que pelo resultado; 4) os dados são analisados de forma intuitiva; e 5) o significado é de importância vital na abordagem qualitativa.

A produção de dados aconteceu por meio da segunda edição do curso de formação continuada a distância: "QR Code: desafios e potencialidades para o ensino e aprendizagem", oferecido pela Rede Colabora da Universidade Federal de Pelotas. O curso foi oportunizado aos professores da rede pública do Brasil e aconteceu via ambientes virtuais de aprendizagem (moodle). Desenvolvido durante os meses de abril e maio de 2020, teve 210 inscritos, e destes 114 concluíram o curso. Importante mencionar que os relatos apresentados nos resultados comportam a transcrição diplomática dos registros dos professores sobre a prática desenvolvida e o nome desses profissionais é fictício.

Em relação ao perfil dos concluintes do curso, destaca-se que expressiva maioria dos inscritos (86\%) era do Rio Grande do Sul, e os demais, $14 \%$, oriundos de estados como Amazonas, Ceará, Goiás, Minas Gerais, Mato Grosso, Pará, Paraíba, Pernambuco e Paraná. Desses, 99 são mulheres e 15 são homens, com idade média de 40 anos. Sobre a formação, 33 são licenciados em Matemática; 30, em Pedagogia; 11, em Letras/ Português; e os demais formaram-se em diferentes licenciaturas: Geografia, História, Espanhol, Inglês, Artes Visuais, Física, Ciências Biológicas, Computação, Química, Educação no Campo, Educação Física e Ciências Exatas. Em relação à pósgraduação, 88 têm pelo menos uma especialização; 41, mestrado; e 4, doutorado. Considerando que os participantes atuam em mais de um nível de ensino, os dados são: 21 atuam na Educação Infantil; 34, nos anos iniciais do Ensino Fundamental; 73, nos anos finais do Ensino Fundamental; 25, no Ensino Médio; 19, na Educação de Jovens e Adultos; 1, em curso técnico e 21, em funções que não são de ensino (direção, orientação, supervisão e coordenação de laboratório). 
O QR Code ou código QR é a abreviação de "Quick Response" e significa, em português, que resposta rápida é capaz de armazenar um grande volume de informações. Para decodificar esse tipo de código, utiliza-se a câmera fotográfica de um smartphone e um aplicativo QR Code Reader, leitor de QR Code, conforme Figura 1. A fim de acessar o conteúdo, é necessário escanear a imagem do QR Code, o que pode ser feito mesmo sem internet.

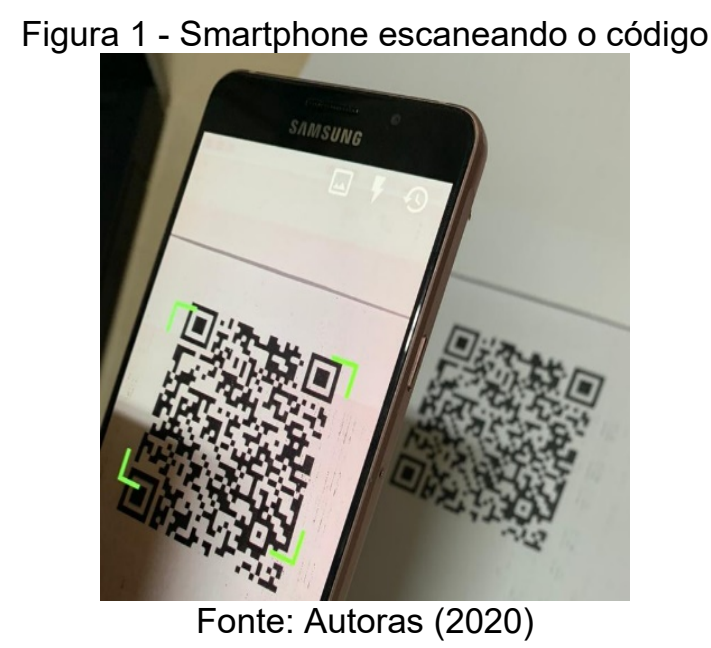

A formação continuada ofertada aos professores foi organizada em 4 módulos, conforme Quadro 1. No quadro, é apresentado cada módulo, seu objetivo, os materiais disponibilizados, bem como as tarefas que foram solicitadas aos participantes. Cumpre mencionar que as videoaulas 1, 2, 3, 4 e 5 foram produzidas pelos ministrantes do curso e, em cada módulo, foram abertos fóruns com o objetivo de esclarecer dúvidas dos participantes. Essa formação privilegiou teoria e prática e oportunizou aos participantes reflexões sobre as tecnologias, em especial, sobre a prática com o código.

Quadro 1: Informações sobre a formação continuada

\begin{tabular}{|c|c|c|c|}
\hline & Objetivo & $\begin{array}{c}\text { Materiais } \\
\text { disponibilizados }\end{array}$ & Tarefas solicitadas \\
\hline Módulo I & $\begin{array}{l}\text { Expor uma visão } \\
\text { geral sobre a } \\
\text { importância do uso } \\
\text { das TD no ensino. }\end{array}$ & $\begin{array}{l}\text { Uma videoaula e } \\
\text { um artigo } \\
\text { científico. }\end{array}$ & $\begin{array}{c}\text { Envio de arquivos (dois textos): } \\
\text { uma reflexão pessoal sobre como } \\
\text { se percebe no mundo tecnológico } \\
\text { e outro sobre como as TD são } \\
\text { percebidas na escola em que } \\
\text { atua. } \\
\end{array}$ \\
\hline Módulo II & $\begin{array}{l}\text { Apresentar o QR } \\
\text { Code, bem como o } \\
\text { processo de } \\
\text { decodificação } \\
\text { (leitura) e } \\
\text { codificação } \\
\text { (geração) do código. }\end{array}$ & Três videoaulas. & $\begin{array}{l}\text { Envio de arquivos: um QR Code } \\
\text { contendo um resumo do artigo } \\
\text { lido no módulo I e um texto sobre } \\
\text { as experiências com o uso do } \\
\text { código no ensino (caso conheça). }\end{array}$ \\
\hline Módulo III & $\begin{array}{c}\text { Socializar } \\
\text { experiências com o } \\
\text { uso do QR Code no } \\
\text { ensino. }\end{array}$ & $\begin{array}{l}\text { Uma videoaula, } \\
\text { um vídeo da } \\
\text { internet e um } \\
\text { texto. }\end{array}$ & $\begin{array}{c}\text { Envio de arquivo: texto contendo } \\
\text { o planejamento de uma proposta } \\
\text { pedagógica com o uso do QR } \\
\text { Code, para ser desenvolvida com } \\
\text { os seus alunos. }\end{array}$ \\
\hline Módulo IV & $\begin{array}{c}\text { Oportunizar a } \\
\text { vivência da proposta } \\
\text { pedagógica }\end{array}$ & & $\begin{array}{l}\text { Envio de arquivo: registro por } \\
\text { meio de texto e/ou imagens, e/ou } \\
\text { vídeos, e/ou narrativa digital, }\end{array}$ \\
\hline
\end{tabular}

Revista de Estudos e Pesquisas sobre Ensino Tecnológico, v. 6, Edição Especial Desafios e Avanços Educacionais em Tempos da COVID-19, e151020, 2020. 


\begin{tabular}{|c|c|c|c|}
\hline $\begin{array}{c}\text { planejada no módulo } \\
\text { III e refletir sobre. }\end{array}$ & $\begin{array}{c}\text { sobre como foi a prática } \\
\text { planejada no módulo III, do ponto } \\
\text { de vista do próprio professor e } \\
\text { também do estudante. }\end{array}$ \\
\hline
\end{tabular}

Fonte: Próprias autoras (2020)

Os dados produzidos no momento da inscrição dos participantes e ao longo do curso foram analisados sob a óptica da Teoria Fundamentada (Grounded Theory) - doravante TF -, proposta por Glaser e Strauss (1967). Conforme Pinto (2012), a TF se aproxima do assunto a ser investigado sem uma teoria a ser testada. A teoria evolui durante a pesquisa real e o faz graças à contínua interação entre análise e coleta de dados. O pesquisador analisa os dados de modo a entender determinada situação e como e por que seus participantes agem de determinada maneira, como e por que determinado fenômeno ou situação se desdobra deste ou daquele jeito (GLASER; STRAUSS, 1967).

Considerando que a TF é um método importante para quem trabalha com dados empíricos advindos do ciberespaço, os dados produzidos foram analisados e as seguintes categorias emergiram: 1) professores que não conseguiram desenvolver a proposta com o QR Code; 2) professores que conseguiram desenvolver a proposta com o QR Code: com outro público e com os seus alunos, conforme Figura 2. Tais categorias serão discutidas na próxima seção.

Figura 2 - Categorias de análise

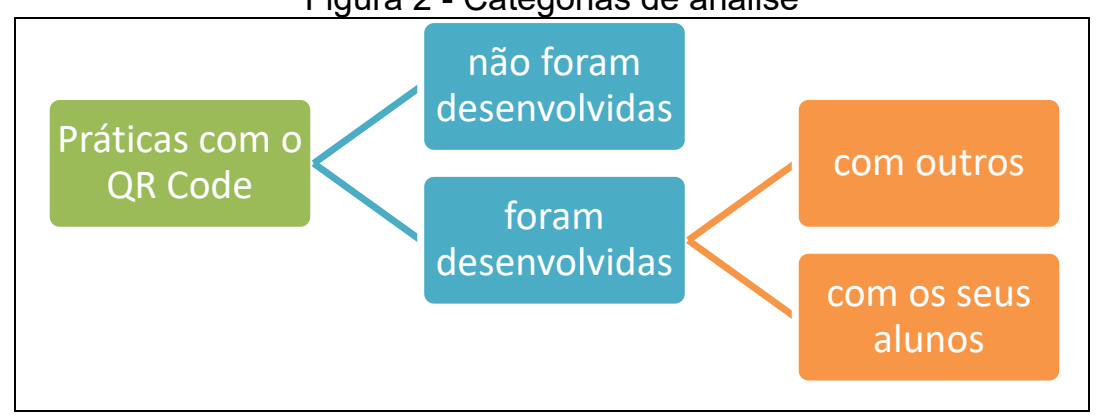

Fonte: Próprias autoras (2020)

\section{Resultados e discussão}

A formação continuada aqui em pauta foi planejada com o intuito de unir teoria e prática. Assim, os professores foram orientados a desenvolver a prática com o QR Code no ensino remoto. No entanto, por meio de mensagens via ambiente virtual e fóruns, diversos docentes trouxeram argumentos justificando a não viabilidade em operar a prática com os seus alunos, visto que ou não estavam tendo contato com os estudantes, ou o trabalho vinha sendo realizado mediante envio de material impresso.

A partir de tais argumentos, a nova orientação foi no sentido de que o planejamento fosse adaptado e desenvolvido com outro público, como: familiares, amigos, entre outros, sempre preservando o distanciamento social. Inicialmente, a discussão começa com o relato de uma participante, Professora Ana, que não conseguiu desenvolver a atividade planejada, alegando que não havia crianças na sua família, nem próximo à sua residência. No entanto, 
segundo a docente, a prática será desenvolvida quando retornarem as aulas presenciais, pois, na visão dela, seus alunos

[...] iriam ficar admirados. Digo isso pois, primeiro, eles teriam o contato com o manuseio de uma ferramenta que não faz parte do seu dia a dia como aluno, o QR Code, e provavelmente não saibam da existência ou o que ele representa, sendo uma novidade para essa faixa etária. Ficariam encantados com a possibilidade de buscar uma informação que não estivesse "visível" e teriam que descobrir seu conteúdo com o celular, objeto "proibido" em sala de aula sem autorização (PROFESSORA ANA).

A professora Ana não desenvolveu a proposta com os seus alunos, mas acredita que eles ficariam admirados com o código, com a possibilidade de chegar a uma informação que não está visível. Ela, também, optou por não desenvolver a prática com os adultos de sua família ou do círculo de amizade. Será que os adultos não estariam dispostos a aprender sobre o código e a se encantar com as descobertas? Afinal, o uso desse código tem se tornado comum para ações como participar de uma promoção, comprar pizza com desconto, mais informações sobre produtos nos supermercados, ou ler informações sobre uma obra no museu (GARCIA et al., 2018). Ademais, em tempos de pandemia, o uso do código se intensificou ainda mais, são os cardápios que estão no formato de um código, são códigos que aparecem na tela do televisor para mais informações sobre campeonatos e times de futebol, bem como durante as lives para doação em valores.

Enquanto a professora Ana optou por não desenvolver a proposta com adultos, Júlia desenvolveu a prática planejada com um familiar adulto. O planejamento havia sido pensado para alunos do $6^{\circ}$ ano de uma escola municipal e para uma turma da EJA do Instituto Federal Sul-rio-grandense. No entanto, não foi possível aplicar, já que uma das instituições de ensino estava com as aulas totalmente paralisadas e, na outra, o contato com os estudantes não era de modo síncrono. Segue o relato da professora:

Inicialmente achei que seria pouco viável de desenvolver esta aula em rede pública de ensino [...] creio que eu teria bem mais obstáculos para lidar, como necessidade de wifi, computadores, manuseio de programas, celulares [...] o qr code facilitou para que o aluno imergisse nestas figuras tridimensionais dos sites, possibilitou que fizesse visitas guiadas com mais facilidade devido ao acesso aos links. Minha aula ficou bastante interativa com esta ferramenta e ver o aluno pesquisando também tornou o estudante ser ativo durante a prática pedagógica. [...] Senti uma grande alegria ao ver a ferramenta aliando de modo interdisciplinar a ciência com a arte. Pensei na possibilidade de criar a narração da história dos personagens com o qr code, entre outras ideias que poderiam ser exploradas numa exposição dos trabalhos (PROFESSORA JÚLIA).

Os registros da professora Julia vão ao encontro do que se espera com o uso da TD, principalmente quando escreve que a prática desenvolvida oportunizou ao participante pesquisar e se tornar ativo no processo de ensino e aprendizagem. Nesse sentido, de acordo com Moran (2018, p. 12), "A combinação de metodologias ativas com tecnologias digitais móveis é hoje estratégia para a inovação pedagógica". 
Outros docentes também adaptaram a prática planejada e a desenvolveram, como foi o caso do professor José, que teve como participante um jovem do seu círculo de amizade. Consoante o professor, o que chamou mais atenção do participante foi o fato de a atividade ser entregue em um QR Code, o que já foi identificado como um desafio a ser descoberto. Em relação à sua experiência, o professor destaca:

[...] foi muito interessante, tinha utilizado o QR Code anteriormente, mas não pensando em atividades de ensino e aprendizagem. A experiência me permitiu ver diferentes possibilidades e acrescentar ao meu repertório de ferramentas didáticas. Não tive dificuldades em desenvolver a prática, ao contrário, encarei todo o processo com um grande desafio, que ao fim do curso, foi superado (PROFESSOR JOSÉ).

Uma situação peculiar foi apresentada pela professora Mara. Devido à dificuldade de acesso à internet que a maioria dos seus alunos tem, a docente envia material impresso, por isso optou por realizar a prática com o QR Code com cinco colegas professoras, porém apenas uma delas concluiu a prática. Desse modo, a professora participante da formação traz as seguintes considerações:

Na minha opinião é uma ferramenta didática interessante que permite levar o ensino a lugares remotos, desde que tenha acessibilidade à internet, uma prática que economiza tempo, pois na maioria dos telefones já é possível ter o aplicativo. Também economiza papel impresso.

Gostei muito de trabalhar com o aplicativo do QR Code, porque é uma maneira de trazer uma tecnologia nova para aulas. Pretendo sempre que possível fazer algum trabalho que envolva esta ferramenta em sala. E espero que a curiosidade dos professores seja maior que a sua resistência em aprender o novo (PROFESSORA MARA).

O registro da docente Mara suscita aspectos importantes do QR Code, entre eles a economia de tempo e de papel, bem como a resistência de alguns professores em conhecer o novo. Essa resistência é muito comum, e, em se tratando das tecnologias digitais, ela não é infundada, conforme cita Kenski (2013). A autora salienta que a sobrecarga de trabalho dos professores se intensificou com o uso e as facilidades das TD, uma vez que, agora, é esperado desse profissional atender os estudantes mesmo fora do seu horário de trabalho, por exemplo.

No contexto dessa discussão, é importante ressaltar que, em tempos de pandemia, os professores estão ainda mais sobrecarregados, e um dos motivos é justamente a falta de conhecimento do uso pedagógico das TD. O momento exigiu sair da zona de conforto e apropriar-se das tecnologias digitais para, de modo efetivo, fazer acontecer o ensino remoto, todavia, de acordo com Arruda (2020), é preciso considerar que os docentes estão confinados, que possuem famílias e que também se encontram em condições de fragilidades em suas atividades.

Quanto aos professores que conseguiram desenvolver a prática com os seus alunos, serão destacadas três situações. A professora Paula elaborou a prática para os estudantes do sexto ano do ensino fundamental de uma escola da rede pública e os orientou por meio do grupo de WhatsApp da turma, no qual, além 
da professora e de alguns estudantes, estão também inseridos alguns pais cujos filhos não possuem esse aplicativo de envio de mensagens. No momento em que a atividade do QR Code foi proposta à turma, um pai manifestou o desejo de receber atividades no formato "tradicional", alegando que seu celular não teria memória suficiente para baixar o aplicativo leitor de QR Code. Em seguida, outros pais fizeram o mesmo pedido.

A docente Paula sublinha que os estudantes não manifestaram nenhum estranhamento referente ao uso da tecnologia, confirmando as discussões estabelecidas no decorrer do curso de que os estudantes de hoje são nativos digitais. Para Serres (2013), são a geração polegar, visto que tecla com os polegares, habita o virtual, manipula várias informações ao mesmo tempo e não conhece, nem sintetiza da mesma maneira como seus antepassados. Ainda, segundo a professora:

A maior dificuldade continua sendo o acesso à tecnologia, a grande maioria acessa a tecnologia de maneira restrita, aparelhos com armazenamento insuficiente, qualidade de Internet precária e, a visão dos pais sobre formas diferentes de ensinar e aprender, muitos acham que os filhos devem passar pelas mesmas experiências de ensino e de aprendizagem que eles próprios passaram na escola, sem considerar as diferenças (PROFESSORA PAULA).

As dificuldades de acesso a uma internet de qualidade apontadas pela professora Paula aparecem também nos registros da professora Sandra. Esta docente desenvolveu sua prática com um grupo de voluntários do $9^{\circ}$ ano, porque, devido à falta de acesso à internet, nem todos puderam participar do que foi proposto. A professora formou um grupo no WhatsApp e explicou o funcionamento da atividade, bem como convidou o grupo para ser monitor dessa atividade em sala de aula, quando as aulas presenciais forem retomadas.

Uma alternativa que usei para que o trabalho fosse bem recebido pelos estudantes, já que não se tratava de uma aula efetiva da turma, foi trazer uma pincelada de humor e a possibilidade de escolherem livremente o conteúdo que gostariam de revisar. Isso fez com que a atividade fosse significativa e ao mesmo tempo divertida, o que foi possível verificar nas conversas e bate papos com os estudantes. Um aspecto que chamou a atenção foi o fato de alguns deles terem escolhido o conteúdo que tiveram dificuldade quando trabalhado nas aulas presenciais do ano anterior.

A participação, o desenvolvimento e os resultados da atividade foram avaliados positivamente tanto pelos estudantes quanto por mim, professora. Foi uma experiência enriquecedora de aprendizagem para todos nós! (PROFESSORA SANDRA).

A avaliação positiva tecida pela professora Sandra e pelos seus estudantes a respeito da prática com o QR Code está em sintonia com o relato de Pinto, Felcher e Ferreira (2016). Esses autores desenvolveram uma prática com uma turma de $3^{a}$ série do Curso Normal, visando trabalhar de maneira diferente a biografia do professor e escritor Malba Tahan. No contexto da proposta colocada em prática pela docente, os estudantes fizeram a leitura e também criaram códigos, mencionando o quão importante foi a prática, pois oportunizou mais conhecimento sobre o uso da tecnologia em sala de aula, principalmente 
uma tecnologia que está presente no dia a dia, mas até então não era conhecida pelos estudantes.

A situação da professora Rita é diferente das demais apresentadas anteriormente. Atuando em duas escolas, planejou a prática para aquela que estava trabalhando de modo remoto, inclusive desenvolvendo aulas síncronas. Dessa maneira, a prática com o QR Code foi desenvolvida com as turmas de $7^{\circ}$ ano, cinco turmas, um total de 144 alunos. Destes, cerca de 120 estudantes desenvolveram a atividade proposta na disciplina de Matemática, possibilitando que a docente avaliasse de forma positiva o uso do QR Code, já que houve bastante participação dos estudantes: "penso que se fosse na sala de aula, com QR Codes diferentes, seria ainda mais interessante" (PROFESSORA RITA).

Importante mencionar que aos participantes foi solicitada uma proposta de uso do QR Code para a sala de aula, os quais tiveram liberdade para criar e adequar ao seu contexto. Como resultado, observou-se uma diversidade de uso do código, tanto apresentado pelos professores aos estudantes, quanto gerados pelos próprios estudantes e, também, inseridos em jogos. A Figura 3 destaca quatro usos do QR Code: 1) apresentação de um código pelo professor, o qual leva a um link para uma viagem pela história da Arte, possibilitando ao estudante visualizar as figuras tridimensionais e fazer visitas guiadas; 2) após explanação do professor sobre a tarefa, o estudante desenvolveu uma pesquisa cientifica sobre um animal. No caso em tela, escolheu o peixe abissal e o apresentou no formato de um código; 3) criação de um jogo com QR Code, por meio do qual a professora associou a pandemia do novo Coronavírus à tecnologia digital, sendo que as pistas do jogo estão em formato de código; e 4) a professora solicitou aos estudantes pesquisar quais as plantas medicinais mais utilizadas em casa, preparar mudas para plantar na escola e identificá-las com o QR Code.

Figura 3 - Atividades com o QR Code

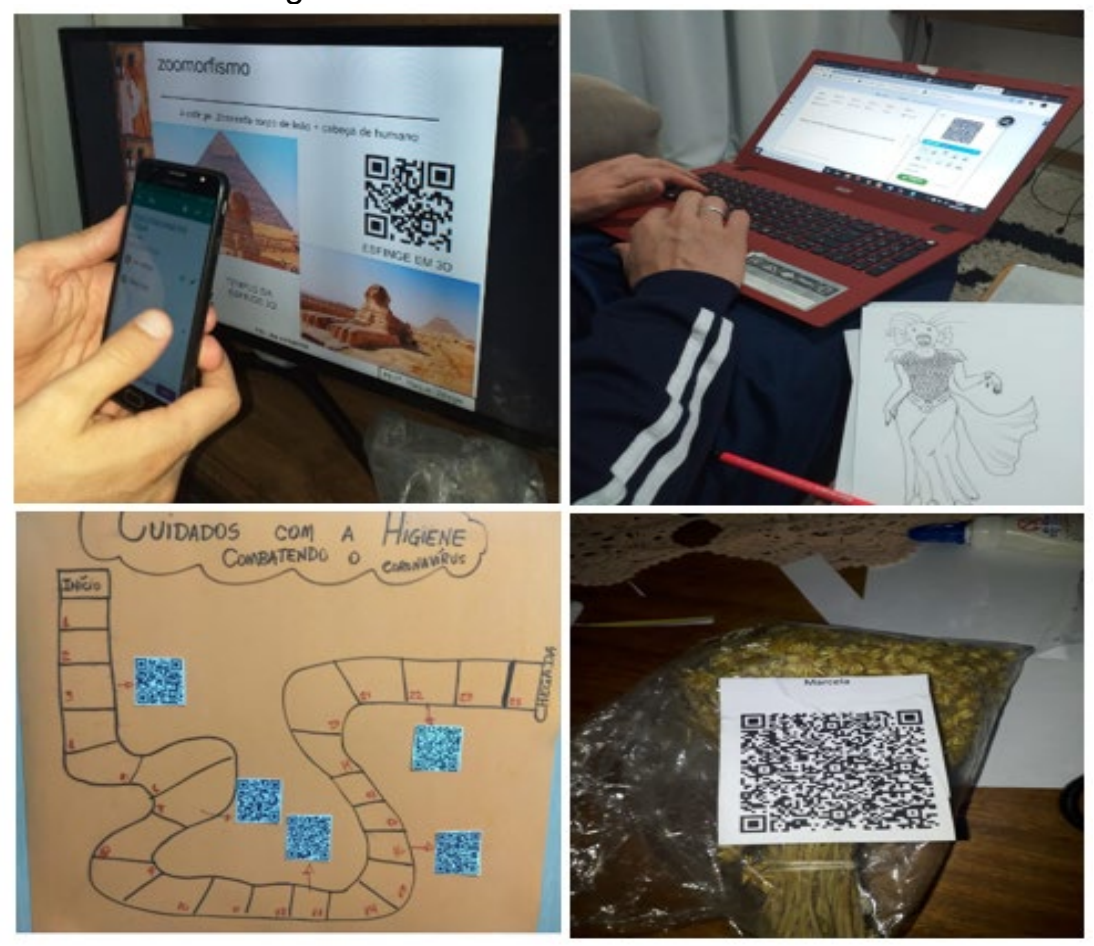

Fonte: Próprios autores (2020)

Revista de Estudos e Pesquisas sobre Ensino Tecnológico, v. 6, Edição Especial Desafios e Avanços 12Educacionais em Tempos da COVID-19, e151020, 2020. 
Revisitando os registros dos professores descritos nesta seção, com frequência aparecem protestos quanto à dificuldade de acesso à internet pelos alunos. Nesse sentido, vale refletir sobre o uso das tecnologias digitais para mediar o processo de aprendizagem e, assim, manter o vínculo entre aluno e escola. No Brasil, segundo Arruda (2020), as regiões Norte e Nordeste concentram os maiores níveis de pobreza da população e, dessa forma, o menor número de acesso à internet e equipamentos tecnológicos, conforme dados da Pesquisa Nacional por Amostra de Domicílios (PNAD). O acesso à internet, de acordo com esses dados, em se tratando de jovens entre 10 e 13 anos, mantém-se na faixa de $92 \%$ nas regiões Sul, Sudeste e Centro Oeste e cai para $71 \%$ na região Norte e 79\% na região Nordeste (ARRUDA, 2020).

Os problemas de falta de equipamento e de acesso à internet em tempo nenhum estiveram tão no auge das discussões e preocupações nos diversos países e relacionam-se diretamente às questões de ensino durante a pandemia. Consoante Santos Júnior e Monteiro (2020), é preciso conhecer as condições de acesso dos estudantes às tecnologias e, principalmente, à internet, para dar continuidade aos seus estudos de forma remota. Conforme os autores, esse processo de integração das tecnologias digitais precisa garantir a participação de todos, para evitar a exclusão educacional (SANTOS JUNIOR; MONTEIRO, 2020).

Com o objetivo de evitar ou amenizar a exclusão educacional em tempos de pandemia, os países buscaram diferentes alternativas. Para Arruda (2020), os Estados Unidos, por exemplo, apresentam situações distintas quanto às estratégias utilizadas, mas a grande maioria adotou a educação mediada por tecnologias digitais. Países como México, Chile e Uruguai fazem uso de tecnologias digitais na educação em todos os níveis, por meio de aplicativos gratuitos, programas de televisão, plataformas de aprendizagem, entre outros. O modelo de funcionamento da educação básica ficou sob os cuidados dos estados, e não do Ministério da Educação, numa inequívoca demonstração do quanto esse órgão tem, na prática, pouca liderança e um limitado poder decisório (ARRUDA, 2020).

No estado do Rio Grande do Sul, onde se concentra o maior número de participantes da formação continuada, as férias de inverno foram antecipadas para o mês de maio. Após o período de férias, o estado adotou a Plataforma Google Classroom como ambiente virtual de aprendizagem (SECRETARIA DA EDUCAÇÃO, 2020). E para resolver problemas de acesso à plataforma, no final de agosto, o governador do estado anunciou internet móvel gratuita para todos os professores e estudantes da rede estadual, sendo preciso apenas instalar o aplicativo Escola RS.

$\mathrm{Na}$ verdade, o setor educacional vem sofrendo de modo intenso os efeitos da pandemia e inclusive o aumento da desigualdade educacional vem causando receio. Para minimizar tais efeitos, Arruda (2020) ressalta a importância do ensino remoto, visando manter o vínculo entre estudantes, professores e demais profissionais da educação. Conforme o autor, o não oferecimento do ensino remoto pode representar o afastamento por muitos meses de estudantes dos espaços escolares (físicos e virtuais), comprometendo a qualidade da 
educação, em grau bem maior que as limitações das oportunidades que vêm sendo oferecidas (ARRUDA, 2020).

Por fim, destaca-se que "[...] as respostas educacionais por meio das tecnologias demonstraram importantes iniciativas no sentido de considerar a excepcionalidade do momento" (ARRUDA, 2020). Desse modo, é impossível pensar em uma educação que prescinda das TD, seja em tempos de ensino remoto ou não. As TD são fundamentais porque ampliam as possibilidades de aprendizagem, por isso, cada vez mais, devem ocupar espaço nos debates educacionais dos mais diversos níveis do ensino e, também, devem constituirse em preocupação dos governantes e gestores da educação.

\section{Considerações finais}

As TD, antes barradas por muitas escolas, tornaram-se a solução para os problemas educacionais em tempos de pandemia, tanto no sentido de manter o vínculo entre o estudante e a escola, quanto para o desenvolvimento cognitivo dos estudantes. Porém, a pandemia tornou ainda mais visível a desigualdade social no nosso país, visto que as tecnologias digitais presentes no nosso dia a dia não estão em todos os lugares e lares do Brasil. Dito de outra forma, muitos são os brasileiros que não têm acesso à internet, ou acesso a uma internet de qualidade. Há também um número expressivo de brasileiros que não possuem um computador pessoal, e há os que não possuem aparelho celular, embora em número restrito.

Além da dificuldade de acesso à internet, as férias de inverno antecipadas em escolas estaduais do Rio Grande do Sul e a paralisação das aulas em algumas redes dificultaram colocar em prática o planejamento com o QR Code, elaborado pelos professores participantes da formação continuada. Importante salientar que, nos meses de abril e maio, ainda pairavam muitas dúvidas sobre oferecer ou não o ensino não presencial e de que modo deveria ser feito. Nesse contexto, o professor vem se reinventando, assim como no curso de formação continuada, no qual muitos buscaram outros públicos para desenvolver o planejado e aprender mais, com vistas a levar novas possibilidades de aprendizagem para os seus estudantes.

Portanto, é necessário e urgente que o ensino seja reavaliado, sobretudo o ensino presencial, de modo que as TD sejam um meio significativo em prol da aprendizagem, para além dos tempos de pandemia. Para tanto, é fundamental que investimentos em equipamentos tecnológicos e internet, bem como formação de professores para o uso das TD sejam prioridade dos governantes. Afinal, o momento vivido é incerto e não se sabe se o Brasil enfrentará uma segunda onda da pandemia, ou se novas pandemias virão para quebrar ainda mais paradigmas e evidenciar o quão a educação é indispensável à sociedade e, nela, o lugar das tecnologias digitais. 


\section{Referências}

ARRUDA, E. P. Educação remota emergencial: elementos para políticas públicas na educação brasileira em tempos de Covid-19. EmRede - Revista de Educação a Distância, v. 7, n. 1, p. 257-275, 2020.

BACICH, L.; MORAN, J. Aprender e ensinar com foco na educação híbrida. Revista Pátio, n 25, junho, 2015, p. 45-47.

BACICH, L.; MORAN, J. Metodologias ativas para uma educação inovadora: uma abordagem teórico-prática. Porto Alegre: Penso, 2018.

$\mathrm{BACICH}$, L. Ensino híbrido: muito mais do que unir aulas presenciais e remotas. Inovação na educação, [S. I.], 6 jun. 2020. Disponível em: $<$ https://lilianbacich.com/2020/06/06/ensino-hibrido-muito-mais-do-que-uniraulas-presenciais-e-remotas/>. Acesso em: 11 set. 2020.

BASTOS, D. L.; RAPKIEWICZ, C.; BENVENUTI, J. Integrando QR Code na educação na EJA: um projeto-piloto voltado para entendimento da língua portuguesa. In: WORKSHOP DE INFORMÁTICA NA ESCOLA, 22., 2016. Uberlândia. Anais..., Uberlândia, 2016. Disponível em: <https://www.brie.org/pub/index.php/wie/article/view/6640/4551>. Acesso em: 17 dez. 2020.

BODGAN, R. C.; BIKLEN, S. K. Investigação qualitativa em educação: uma introdução à teoria e aos métodos. Porto: Porto Editora, 1994.

BORBA, M.; VILLARREAL. Humans-with-Media and the Reorganization of Mathematical Thinking. New York: Springer, 2005.

BORBA, M. C; SILVA, R. S. R; GADANIDIS, G. Fases das tecnologias digitais em educação matemática. Belo Horizonte: Autêntica, 2015.

BORBA, M. C.; ALMEIDA, H. R. F. L.; GRACIAS, T. A. S. Pesquisa em ensino e sala de aula: diferentes vozes em uma investigação. Belo Horizonte: Autêntica, 2018.

BRASIL. Base Nacional Comum Curricular. Ministério da Educação, [S. I.], 2017. Disponível em: <http://basenacionalcomum.mec.gov.br/abase/>. Acesso em: 28 ago. 2020.

BRASIL. Portaria $N^{\circ} 343$, de 17 de março de 2020. Diário oficial da União, Brasília, DF, 2020. Disponível em: <http://www.in.gov.br/en/web/dou//portaria-n-343-de-17-de-marco-de-2020-248564376>. Acesso em: 28 set. 2020.

FELCHER, C. D. O.; PINTO, A. C. M.; FOLMER, V. Tecnologias digitais no ensino da matemática e formação de professores: possibilidades com o QR Code Reader. Revista de Estudos e Pesquisas sobre Ensino Tecnológico (EDUCITEC), v. 4, n. 8, 2018.

GARCIA, D. O. et al. Gamificação, QR Code e Aprendizagem no Ensino Superior Híbrido. CIET: EnPED, 2018. 
GLASER, B. G.; STRAUSS, A. L. The Discovery of Grounded Theory: strategies for qualitative research. New York: Aldine de Gruyter, 1967.

KENSKI, V. M. Tecnologias e tempo docente. Campinas, SP: Papirus, 2013.

LÉVY, P. As tecnologias da inteligência: o futuro do pensamento na era da informática. São Paulo: Editora 34, 1993.

MALTEMPI, M. V. Educação matemática e tecnologias digitais: reflexões sobre prática e formação docente/Mathematics education and digital technologies: Reflexions about the practice in teacher education. Acta Scientiae, v. 10, n. 1, p. 59-67, 2008.

MORAN, J. Metodologias ativas para uma aprendiz/agem mais profunda. In.: BACICH, L.; MORAN, J. Metodologias ativas para uma educação inovadora: uma abordagem teórico-prática. Porto Alegre: Penso, 2018.

NICHELE, A. G.; SCHLEMMER, E.; RAMOS, A. F. QR Codes na Educação em Química. RENOTE. Revista Novas Tecnologias na Educação, v. 13, p. 1, 2015.

PIMENTEL, F. S. C.; FEITOZA, M. J. S. O uso da tecnologia móvel (celular) no contexto educacional. Revista Educação a Distância e Práticas Educativas Comunicacionais e Interculturais, São Cristóvão, v. 17, n. 3, p. 129-139, 2017.

PINTO, C. M. A teoria fundamentada como método de pesquisa para ambientes virtuais de aprendizagem. Caminhos em Linguística Aplicada, v. 7, n. 2, p. 78-96, 2012.

PINTO, A. C. M.; FELCHER, C. D. O; FERREIRA, A. L. A. Considerações sobre o uso do aplicativo QR CODE no ensino da matemática: reflexões sobre o papel do professor. In: ENCONTRO NACIONAL DE EDUCAÇÃO MATEMÁTICA, 12., 2016, São Paulo, Anais..., 2016. São Paulo, 2016.

SANTOS JUNIOR, V. B.; MONTEIRO, J. C. S. Educação e covid-19: as tecnologias digitais mediando a aprendizagem em tempos de pandemia. Revista Encantar-Educação, Cultura e Sociedade, v. 2, p. 1-15, 2020.

SAPRUDIN, A.; GOOLAMALLY, N.; LATIF, L. A. Embedding QR codes in the teaching and learning process. In: Seminar Kebangsaan Pembelajaran Sepanjang Hayat, p. 201-210, 2014.

SECRETARIA DA EDUCAÇÃO. Portal Educação Rio Grande do Sul, [S. I.], 2020. Disponível em: <http://portal.educacao.rs.gov.br/Main/Home/lndex/>. Acesso em: 5 out. 2020.

SCHIEHL, E. P.; GASPARINI, I. Contribuições do Google Sala de Aula para o ensino híbrido. RENOTE-Revista Novas Tecnologias na Educação, v. 14, n. 2, 2016.

SERRES, M. Polegarzinha. Rio de Janeiro: Bertrand Brasil, 2013. 
WHO - World Health Organization. Coronavirus disease (COVID-19) situation report-102, [S. I.], 2020. Disponível em: <https://www.who.int/docs/defaultsource/coronaviruse/situation-reports/20200501-covid-19-

sitrep.pdf?sfvrsn=742f4a18_2> Acesso em: 12 set. 2020.

WHO - World Health Organization. Coronavirus Disease (COVID-19) Dashboard, [S. I.], $2020 . \quad$ Disponível em: <https://covid19.who.int/region/amro/country/br>. Acesso em: 12 out. 2020.

Recebido: $21 / 10 / 2020$

Aprovado: 15/12/2020

Como citar: FELCHER, C. D. O.; PINTO, A. C. M.; ALVES, R. S. Os desafios do uso do QR Code encontrados por professores no ensino remoto. Revista de Estudos e Pesquisas sobre Ensino Tecnológico (EDUCITEC), v. 6, Ed. Esp. Desafios e avanços educacionais em tempos da COVID-19, e151020, 2020.

Direito autoral: Este artigo está licenciado sob os termos da Licença Creative CommonsAtribuição 4.0 Internacional.

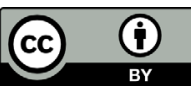

